\title{
Effect of sweetener combination and storage temperature on physicochemical properties of sucrose free white chocolate
}

\author{
Laura T. Rodriguez Furlán ${ }^{\mathrm{a}, *}$, Yanina Baracco ${ }^{\mathrm{a}}$, Javier Lecot ${ }^{\mathrm{b}}$, Noemi Zaritzky ${ }^{\mathrm{b}}$, Mercedes E. Campderrós ${ }^{\mathrm{a}}$ \\ ${ }^{a}$ Institute of Chemical Technology Research (INTEQUI)-CONICET, Faculty of Chemistry, Biochemistry and Pharmacy (Universidad Nacional de San Luis), Ejército de los Andes \\ 950-5700, San Luis, Argentina \\ ${ }^{\mathrm{b}}$ Center of Research and Development in Food Cryotechnology, CIDCA (Universidad Nacional de La Plata-CONICET), La Plata, Buenos Aires, Argentina
}

\section{A R T I C L E I N F O}

\section{Article history:}

Received 14 September 2016

Received in revised form 19 January 2017

Accepted 1 March 2017

Available online 2 March 2017

\section{Keywords:}

Free-sugar chocolate

Fat and sugar Bloom

Microstructure

Hardness

Thermodynamic properties

\begin{abstract}
A B S T R A C T
The influence of a combination of sweeteners (Stevia (St) and sucralose (Su)) and storage temperature on thermal properties, microstructure, water content, texture and Bloom of sucrose free white chocolate was investigated. A strong relationship between the microstructure and the highest percentage of Bloom was observed. The samples with $100 \% \mathrm{Su}$ and $50 \% \mathrm{~S}+50 \% \mathrm{Su}$ presented microstructures with channels through which solids and fat could more easily spread to the surface, increasing the fat and sugar Bloom formation. However, $50 \% \mathrm{St}+50 \% \mathrm{Su}$ and $75 \% \mathrm{St}+25 \% \mathrm{Su}$ samples showed a minimum Bloom formation, probably due to its dense microstructure with no void spaces. The differential scanning calorimetry studies demonstrated that the samples containing $100 \% \mathrm{St}$ and $75 \% \mathrm{St}+25 \% \mathrm{Su}$ showed the smallest decrease of melting enthalpy with increasing temperature. Besides, non-isothermal crystallization kinetics was studied by applying Avrami model. The sample $75 \% \mathrm{St}+25 \% \mathrm{Su}$ presented the highest values of activation energy showing the greatest stability in the temperature range studied $\left(7^{\circ} \mathrm{C}-30^{\circ} \mathrm{C}\right)$.
\end{abstract}

(c) 2017 Elsevier Ltd. All rights reserved.

\section{Introduction}

The effect of different parameters on chocolate quality is an important point to consider when formulating a sugar-free chocolate since the lipid phase can be influenced by the presence or absence of sucrose, and its replacement by other high molecular weight components such as Stevia. Cocoa butter crystallizes into six polymorphic forms (I-VI), where form I is the least stable and $\mathrm{V}$, the most desirable form, which may transform into $\mathrm{VI}$, the most stable throughout storage. The most desirable form during the chocolate manufacture is $\mathrm{V}$, which produces the desired glossy appearance, good snap, contraction and enhanced shelf life (Afoakwa, Paterson, Fowler, \& Vieira, 2008a). The expected mouthfeel of chocolate depends on the melting point of the cocoa butter fraction. Form V may transform into form VI; that is responsible for fat Bloom on chocolate, resulting in white spots which consumers interpret as a sign of poor quality, and which reduces the product shelf life (James \& Smith, 2009).

The composition of chocolate plays an important role during its processing, because it defines the different interactions that take

\footnotetext{
* Corresponding author.

E-mail address: furlan.laura@gmail.com (L.T. Rodriguez Furlán).
}

place among ingredients; it determines the final microstructure of the product that influences the melting and crystallization properties and the formation of fat Bloom (Fernandes, Müller, \& Sandoval, 2013). Also, the crystalline state of cocoa butter and the chocolate composition affect the thermal properties in finished products. Differential scanning calorimetry (DSC) is used to characterize changes in chocolate properties like melting and crystalline profiles, and to measure the energy involved in each specific polymorph (Afoakwa et al., 2008a). This information is important to determine the impact of composition on mechanical and thermodynamic properties of chocolate.

Previous studies performed by Rodriguez Furlán, Baracco, Zaritzky, and Campderrós (2016a, 2016b) and Rodriguez Furlán, Baracco, Lecot, Zaritzky, and Campderrós (2017) demonstrated that the replacement of sucrose in white chocolate by the combination of different components, modified their stability and characteristics; because sugar is a multifunctional ingredient with properties of a sweetener, a bulking and texturizing agent. This work provides information on the effects of changes in the composition of free sucrose white chocolate by the replacement of sucrose by different sweeteners like Stevia and sucralose, and storage conditions on the microstructural, melting and crystallization properties, fat and sugar Bloom percentage on the surface, and moisture content of free-sugar white chocolate. 


\section{Materials and methods}

\subsection{Raw materials and sample preparation}

The materials used in the manufacture of white chocolate were: Cocoa Butter (Arcor SAIC, San Luis), whole milk powder (Ylolay, Argentina), skim milk powder (La Serenisima, Argentina), Sucrose (Ledesma SA, Argentina), powder sucralose (Sucaryl Sucralose, Argentina), Stevia powder (Tanki SA, Argentina), vanilla (Alicante, Argentina), Soy Lecithin (Yeruti S.R.L., Argentina).

The white chocolate was produced following the next steps: sugar was milled together with milk powder using a grain mill (Corn-Grain-Cereal-Mill, China) and a grinder. Then, the cocoa butter was melted in a water bath. Sugar, milk powder and cocoa butter were mixed in a planetary mixer (Santini, Italy) during $5 \mathrm{~min}$. Preparation was refined using a multi-hole screw extruder for $1 \mathrm{~h}$ at $35 \pm 1{ }^{\circ} \mathrm{C}$. The conched was performed under constant stirring at $200 \mathrm{rpm}$ at $45 \pm 1{ }^{\circ} \mathrm{C}$ for $7 \mathrm{~h}$. Lecithin and vanilla were added in the last $30 \mathrm{~min}$ of conching. Subsequently was tempered by cooling at $23 \pm 1^{\circ} \mathrm{C}$ and then heated to $28 \pm 1^{\circ} \mathrm{C}$. Samples were molded and cooled for $2 \mathrm{~h}$ at $7 \pm 1^{\circ} \mathrm{C}$. After cooling and stored at room temperature during a period of $24 \mathrm{~h}$, the samples were packaged in sealed bag $(0.25 \mathrm{~cm} \times 0.25 \mathrm{~cm})$ of a flexible material of $\mathrm{P}$ olyester/Aluminum/Polyethylene $\left(\mathrm{O}_{2}\right.$ permeability: $1 \mathrm{~cm}^{3} \mathrm{~m}^{-2}$ day $^{-1}$; water vapor permeability: $3 \mathrm{~g} \mathrm{~m}^{-2} \mathrm{day}^{-1}$, at $\left.20^{\circ} \mathrm{C}\right)$. This material is commonly used to package chocolate in Argentina. Then the samples were stored at ambient relative humidity of $55 \%$.

The basic formulation tested was: Cocoa butter $28 \% \mathrm{w} / \mathrm{w}$; sucrose $47 \% \mathrm{w} / \mathrm{w}$; whole milk powder $14.5 \% \mathrm{w} / \mathrm{w}$; skim milk powder $11 \% \mathrm{w} / \mathrm{w}$; soya lecithin $0.4 \% \mathrm{w} / \mathrm{w}$; vanilla $0.1 \% \mathrm{w} / \mathrm{w}$.

Different sweeteners such as sucralose and Stevia powder were tested in the formulation using an appropriate experimental design.

\subsection{Experimental design}

A mixture experimental design of three components was used to study the influence of the combination of different saccharides as sweetening agents on the quality of the product. For the development of white chocolate formulations, the sucrose content was replaced partially or completely based on its equivalent concentration with zero-calorie sweeteners ( $1 \mathrm{~g}$ of Stevia $\equiv 15 \mathrm{~g}$ of sucrose; $1 \mathrm{~g}$ of sucralose $\equiv 7.5 \mathrm{~g}$ of Sucrose). The independent variables were: sucrose $\left(x_{1}, S\right)$, sucralose $\left(x_{2}, S u\right)$ and Stevia $\left(x_{3}, S t\right)$ and their proportions were calculated based in the total amount of the saccharide in the mixture ranged from 0 to $100 \%$. The polynomial equation that fitted the experimental data (mixture model for three components) can be represented by:

$$
\begin{aligned}
y= & b_{1} x_{1}+b_{2} x_{2}+b_{3} x_{3}+b_{12} x_{1} x_{2}+b_{13} x_{1} x_{3}+b_{23} x_{2} x_{3} \\
& +b_{123} x_{1} x_{2} x_{3}
\end{aligned}
$$

where $y_{i}$ is the dependent variable and represents the value of the property of interest (fat and sugar Bloom percentage), $b_{i}$ are the parameters estimated by the model and $x_{1}=$ sucrose, $x_{2}=$ Stevia and $x_{3}=$ sucralose are the independent variables and represent the equivalent concentrations with respect to sucrose sweetness, with $\sum x_{i}=1$ (Ferreira et al., 2007).

From the response of the system to the replacement of sucrose, the graphs of triangular response surface were constructed based on the variable of interest using the Statistical 8 software.

Besides the formulations proposed in the experimental design another formulation was tested with $75 \%$ sucralose and $25 \%$ Stevia, since the concentration and integration of these components in the chocolate matrix had a great influence on the final product properties.

\subsection{Chemical determinations}

Chemical composition of white chocolate was tested after seven days of storage at room temperature. Moisture content by gravimetric method (AOAC 925.10), ash by incineration (AOAC 945.46 ); protein content by determination of total nitrogen by the Kjeldahl method using a Digestion Blocks and a semiautomatic Distiller (Selecta, Spain) with a conversion factor of 6.25 (AOAC 991.22); fat content by Soxhlet extraction (AOAC 945.39) carbohydrate was determined by difference considering the fiber content negligible. In addition, the moisture content of the samples stored at $20^{\circ} \mathrm{C}$ were determined and registered during 24 months by triplicate.

The peroxide index of the chocolate samples was determined by the following method: the samples were defatted employing $50 \mathrm{ml}$ of a mixture of chloroform/methanol (95:5) per eight grams of grated chocolate. This mixture was placed in centrifuge tubes, vigorously stirred and centrifuged at $3000 \mathrm{rpm}$ during $30 \mathrm{~min}$. The solvent fraction was decanted and solvent was evaporated in a bath under constant air flow, obtaining fatty extract. Extracted fat $(5 \mathrm{~g})$ was placed in a $100 \mathrm{ml}$ flask and dissolved in $30 \mathrm{ml}$ of an acetic acid-chloroform solution (3:1). Then, $0.5 \mathrm{ml}$ of a saturated solution of KI was added. It was left to stand in the dark for 2 min with stirring and then $30 \mathrm{ml}$ of water were added. The solution was titrated with $1 \mathrm{ml}$ of soluble starch indicator solution at $1 \%$ freshly prepared. The liberated iodine was titrated with $0.01 \mathrm{~N} \mathrm{Na}_{2} \mathrm{~S}_{2} \mathrm{O}_{3}$ until blue color disappeared. The results were expressed in meq $\mathrm{O}_{2}$ per $\mathrm{kg}$ of fat (Vercet, 2003).

Acidity index was determined by titration previous dissolution of the sample in ethyl alcohol at 50\% (v/v) using phenolphthalein as indicator and a solution of $0.1 \mathrm{~N}$ sodium hydroxide as titrating solution. Acidity index was calculated using the following expression:

$A I=V \times N \times$ meq oleci acid $\times \frac{100}{w}$

where $w$ is the sample weight; $V$ is the spent volume and $N$ is the $\mathrm{NaOH}$ normality.

\subsection{Scanning electron microscopy}

The microstructure of white compound chocolate was analyzed by scanning electron microscopy with a SEM, LEO1450VP equipment (Zeiss, Germany). The samples were mounted on doublesided adhesive carbon on aluminum sample holders. The micrographs were determined under VP mode (variable pressure), using $300 \times$ and $700 \times$ magnifications. Samples were maintained under vacuum at $70 \mathrm{~Pa}$ (Sammons \& Marquis, 1997).

\subsection{Texture measurements}

The hardness $(\mathrm{N})$ of white chocolate samples stored at $20^{\circ} \mathrm{C}$ during 24 months was measured every 7 months using a TMSTOUCH texture analyzer (Food Technology Corporation, USA) with a penetration probe whit a $50 \mathrm{~N}$ load cell. Maximum penetration forces through a sample $(30 \times 30 \mathrm{~mm}$, depth $10 \mathrm{~mm})$ were determined with 10 replications at a pre-speed of $30 \mathrm{~mm} / \mathrm{min}$, test speed of $90 \mathrm{~mm} / \mathrm{min}$, post-speed of $600 \mathrm{~mm} / \mathrm{min}$, penetrating $4 \mathrm{~mm}$ (Afoakwa et al., 2008a; Afoakwa, Paterson, Fowler, \& Vieira, 2009).

\subsection{DSC: determination of melting and crystallization properties}

Melting and crystallization properties were determined by differential scanning Calorimetry (DSC, Q100DTA Instrument). Samples ( $\cong 5 \mathrm{mg}$ ) were loaded into $40 \mu \mathrm{l}$ capacity pans and sealed 
with a sample press. Pans were tempered at $5{ }^{\circ} \mathrm{C}$ and heated at $3{ }^{\circ} \mathrm{C} / \mathrm{min}$ from 5 to $55^{\circ} \mathrm{C}$ in a $\mathrm{N}_{2}$ stream. Other tests were conducted cooling at $10^{\circ} \mathrm{C} / \mathrm{min}$ from 55 to $-50{ }^{\circ} \mathrm{C}$ in a $\mathrm{N}_{2}$ stream. Onset temperature $\left(T_{\text {onset }}\right)$, peak temperature $\left(T_{\text {peak }}\right)$, peak width at half height $\left(T_{\text {width }}\right)$ of the melting and crystallization process, and enthalpy of melting $\left(\Delta H_{m}\right)$ and crystallization $\left(\Delta H_{c}\right)$ and crystallization temperature $\left(T_{c}\right)$ were calculated with the TA Universal Analysis software (Afoakwa et al., 2008a). Besides, a stability study was conducted, in which samples were stored at 7,15 and $30^{\circ} \mathrm{C}$ for 100 days and subsequently were tested by DSC.

\subsection{Image analysis: Fat and sugar Bloom development during storage}

The image analysis was performed by taking images using a computer vision system comprised a standard gray box $\left(L^{*}=50\right.$ in CIELab scale) during a period of 100 days of storage $\left(T=15^{\circ} \mathrm{C}\right)$. The inner box had a pattern of illumination consisting of four lamps D65 placed above the sample at a $45^{\circ}$ angle, and a digital camera placed at $90^{\circ}$ (Sony cybershop, USA). The images were analyzed with the software Image-Pro Plus 6.0 (Media Cybernetics Inc, Bethesda, USA) and the statistical analysis performed with GraphPad InStat. For the analysis, the images were color based segmented in two zones: (i) the zone with fat and sugar Bloom formation defined as the sum of whitish background percentage and white specks percentage (white) and (ii) the zone without Bloom (black). The white objects were measured and calculated the percentage of total area of surface Bloom with respect to the total area (Afoakwa et al., 2008a; Briones \& Aguilera, 2005).

\subsection{Color measurement}

The color of the white chocolate surface was measured in three different zones on three chocolate tablets using a spectrophotometer MiniScan EZ. Variation of the surface color $\left(L^{*}, a^{*}\right.$ and $\left.b^{*}\right)$ of each formulation was monitored over time at $15{ }^{\circ} \mathrm{C}$. $L^{*}$ is the lightness component, which ranged from 100 (white) to zero (black), while $a^{*}$ (+redness/-greenness) and $b^{*}$ (+yellowness/-blueness) are to chromatic components. The colorimeter values $L^{*}, a^{*}$ and $b^{*}$ were used to obtain the overall color difference between two samples, as indicated the following equation (Gómez Polo et al., 2016):

$E_{a b}^{*}=\sqrt{\left(L_{2}^{*}-L_{1}^{*}\right)^{2}+\left(a_{2}^{*}-a_{1}^{*}\right)^{2}+\left(b_{2}^{*}-b_{1}^{*}\right)^{2}}$

The average CIELab color difference $\left(E_{a b}^{*}\right)$ of three $E_{a b}^{*}$ units or greater would be detected by the observers the $100 \%$ of the time. Lower values of $E_{a b}^{*}$ like 2.7 , can be detected by the $50 \%$ or $80 \%$ of the observers. Therefore, the acceptability threshold for $E_{a b}^{*}$ was set in a value of $E_{a b}^{*}$ of three units (Lindsey \& Wee, 2007).

\subsection{Statistical analysis}

The test de Tukey and analysis of one way variance was used for establishing the significance of $P<0.05$ between the means of the analyzed values. The statistical analysis was performed by the statistical GraphPad InStat software.

\section{Theory: Avrami kinetics}

The Avrami model (also known as the Johnson-Mehl-AvramiKolmogorov equation, JMAEK, or simply JMA equation) nucleation-growth model is frequently used for analysis of experimental data of non-isothermal crystallization kinetics used to study crystallization kinetics in amorphous solids for thermoanalytical techniques, such as differential scanning calorimetry (DSC), (Arshad \& Maaroufi, 2015; Málek, 1995, 2000).
The kinetics of crystallization is usually studied by differential scanning calorimetry (DSC) under isothermal or non-isothermal conditions (Arshad \& Maaroufi, 2015). The evolution of the relative crystallinity $(X)$ or crystallization fraction can be computed from the latent heat of the exothermic crystallization peaks employing DSC data, in non-isothermal crystallization kinetics as represented in Eq. (4) (Arshad \& Maaroufi, 2015; Chiari, Vadlamudi, Chella, Jeon, \& Alamo, 2007; Ries, Canedo, Monteiro, de Almeida, \& Wellen, 2016):

$X(T)=\frac{\Delta H_{T}}{\Delta H_{\text {Total }}}=\frac{\int_{T_{0}}^{T} J(t) d t}{\int_{T_{0}}^{T_{\infty}} J(t) d t}$

where $J(t)$ is the heat flux obtained directly from the area of the exothermic DSC peak recorded, $\Delta H_{\text {Total }}$ was obtained from the total area of the exothermic peak, $T_{0}, \mathrm{~T}$ and $T_{\infty}$ are the onset, arbitrary and end crystallization temperatures respectively. The denominator in Eq. (4) represents the total heat for the observed crystallization process, while the numerator is a fraction of that heat, liberated during the interval $T_{0}$ to $T$. This mathematical relationship presupposes that the measured rate of heat release is proportional to the rate of crystallization.

The experiments were performed at constant cooling rate $\phi$ $=\mathrm{dT} / \mathrm{dt}$, so:

$\frac{d X}{d t}=\phi \frac{d X}{d T}$

The JMA equation is frequently used to describe crystallization kinetics of fats (Himawan, Starov, \& Stapley, 2006):

$X(t)=1-e^{(-k t)^{n}}$

where $X(t)$ is the fraction of the transformed material from an amorphous state to a crystalline state; $n$ and $k$ are constants with respect to time, $t$, that depend on the nucleation speed and crystallization kinetics.

The fraction of transformed material under non-isothermal conditions is given by:

$X(t)=1-e\left[\left(\frac{1}{\phi} \int_{0}^{T} k(T) d T\right)^{n}\right]$

where $n$ is the Avrami index and the derivative in non isothermal conditions:

$\frac{d X}{d T}=\left[\frac{k(T)}{\phi}\right] n(1-X)[-\ln (1-X)]^{1-1 / n}$

Considering the previously exposed the reaction rate of the kinetic process can be expressed as a product of temperature dependent rate constant $k(T)$ and the crystallization fraction conversion dependent kinetic model function, $f(X)$ (Arshad \& Maaroufi, 2015; Málek, 2000; Ries et al., 2016):

$\frac{d X}{d T}=\phi \frac{d X}{d T}=\left[\frac{k(T)}{\phi}\right] f(X)$

where $f(X)$ is a function of degree of conversion, called reaction model. Physically, $f(X)$ furnishes information about the mechanism of reaction and is an algebraic expression of the model (Málek, 1995, 2000):

$f(X)=n(1-X)[-\ln (1-X)]^{1-1 / n}$

The rate constant $k(T)$ follows Arrhenius behavior with respect to temperature during the crystallization process (Arshad \& Maaroufi, 2015; Málek, 1995, 2000):

$k(T)=A e^{\frac{-E a}{R T}}$ 
where $E a$ is the energy of activation, and $A$ is the pre-exponential factor (time ${ }^{-1}$ ); $R=8.314 \mathrm{~J} \mathrm{~K}^{-1} \mathrm{~mol}^{-1}$ is the universal gas constant, $\mathrm{T}$ is the absolute temperature.

Both nucleation frequency and crystal growth should have the same temperature dependence, but nucleation frequency is very far from an Arrhenius behavior. However, the nucleation frequency can be neglected when the entire nucleation process take place during early stages of the transformation. Therefore, the crystallization process can be defined only by the crystal growth rate process and assignment an Arrhenius temperature dependence (Málek, 1995). The activation energy term should be considered as an average value taking account the individual energies of all the multiple steps involved in the crystallization process (Arshad \& Maaroufi, 2015).

Taking into account these assumptions, Eq. (10) can be replacing in Eq. (9), the kinetic equation can be written as (Arshad \& Maaroufi, 2015; Málek, 2000; Ries et al., 2016):

$\frac{d X}{d T}=\frac{A}{\phi} e^{\frac{-E a}{R T}} f(X)$

where physically, A describes the frequency of vibrations of the system; $E a$ is the effective reaction energy for the crystallization.

Eq. (11) can be converted to a logarithmic form as (Málek, 2000; Ries et al., 2016):

$\operatorname{Ln}\left(\frac{d X}{d T}\right)=-\frac{E_{a}}{R T}+\ln \left(\frac{A}{\phi}\right)+\ln f(X)$

It can be assumed that the variation of $\ln f(\mathrm{X})$ as a function of temperature can be disregarded due to the small values of $\ln$ $(1-X)(0 \leq X \leq 1)$. In this assumption, a plot of the logarithm of the rate of crystallization $\ln (d X / d t)$ versus the reciprocal of the temperature $T^{-1}$ results in a straight line with slope $-E a / R$, giving the activation energy for the process as suggested Ries et al. (2016).

This procedure was implemented in the present work for relative crystallinities between 3 and 99.8\%.

\section{Results and discussion}

\subsection{Chemical characterization of white chocolate}

Supplementary Table 1 shows the chemical composition of the formulations. The replacement of sucrose leads to a statistically significant increase in fat content. As can be observed for samples $50 \%$ S $+50 \%$ St and $50 \%$ S $+50 \%$ Su the partial sucrose replacement led to an average value of $34.1 \pm 1.3 \% \mathrm{w} / \mathrm{w}$; the total sucrose replacement produced an average value of $48.9 \pm 0.6 \% \mathrm{w} / \mathrm{w}$ for samples $100 \% \mathrm{St}, 100 \% \mathrm{Su}, 50 \% \mathrm{St}+50 \% \mathrm{Su}$, and $75 \% \mathrm{St}+25 \% \mathrm{Su}$. These changes in fat content impacted on the physiochemical properties of chocolate. Differences in protein, moisture and ash content among the studied samples can be directly related to the proportion of replacement of sucrose $(0 \%, 50 \%$ or $100 \%)$, since these components increased with a growing replacement of sucrose. This behavior could be due to the increase in the proportion of sucrose replacement, which generates an increase of the quantities of cocoa butter and milk. In addition, no statistically significant differences were found in the samples with the same fat content or level of sucrose replacement $(P>0.05)$.

Results show that the acidity value depends on the fat content of the sample, increasing with the increase of fat or fatty acid content (Supplementary Table 1 ). The sample $50 \%$ S $+50 \%$ Su presented the highest value of peroxide index $(P<0.05)$, which could be related to the sample microstructure as shown in Section 4.5. The lowest values of peroxide index were obtained with the samples containing $100 \%$ St and $100 \%$ Su. The $100 \%$ St sample presented a lower value of peroxide index than the control $(100 \% \mathrm{~S}),(P<0.01)$.
This may be due to the antioxidant compounds naturally present in the Stevia extract (Kim, Yang, Lee, \& Kang, 2011).

\subsection{Thermal characterization of white chocolate}

The change in the product composition may modify the crystallization temperatures necessary for a proper tempering process to induce the formation of the desirable polymorphic form $\mathrm{V}$ and the completion of liquefaction, hence the importance of the determination of melting and crystallization properties (Afoakwa et al., 2008a, 2009).

Many factors may promote fat Bloom formation on chocolate, that affect the shelf life of the product, such as higher or fluctuating temperatures at which low-melting point crystals melt, migrate to the surface and recrystallize (Altimiras, Pyle, \& Bouchon, 2007; Frazier \& Hartel, 2012).

The results of the analysis of the total energy required to complete the entire process of melting $\left(\Delta H_{T}\right)$ are shown in Fig. 1A. Previous studies performed by Afoakwa et al. (2008a) found differences $(P<0.05)$ among $\Delta H_{\mathrm{T}}$, in which the increase of fat content from $25 \%$ to $35 \%$ produced an increase of $\Delta H_{\mathrm{T}}$. The results presented in Fig. 1A suggest a direct relationship between fat content and $\Delta H_{T}$. The increase of fat content in the samples led to higher $\Delta H_{T}$ values for the three tested storage temperatures $(7,15$ and $30^{\circ} \mathrm{C}$ ). However, the modification of the sweeteners combination also generated changes in the measured areas $\left(\Delta H_{T}\right)$. The samples with total replacement of sucrose and with the same fat content $(48.9 \pm 0.6 \%, w / w$, Fig. $1 \mathrm{~A})$ showed a statistically significant variation among them, especially at the highest temperatures $\left(15^{\circ} \mathrm{C}\right.$ and $30{ }^{\circ} \mathrm{C}$ ). The samples $50 \% \mathrm{St}+50 \% \mathrm{Su}$ stored at $15^{\circ} \mathrm{C}$ presented the largest values of $\Delta H_{T}(P<0.05)$. At a storage temperature of $30{ }^{\circ} \mathrm{C}$, the samples with the highest values of $\Delta H_{T}$ were $100 \% \mathrm{St}$ and $75 \% \mathrm{St}+25 \% \mathrm{Su}(P<0.05)$. The sample $50 \% \mathrm{St}+50 \% \mathrm{Su}$ at a storage temperature of $15^{\circ} \mathrm{C}$ showed a synergistic effect because the binary combination of $\mathrm{St}$ and $\mathrm{Su}$ presented higher values than the samples containing the individual sweetener with the same fat content. Besides, the sample $75 \% \mathrm{St}+25 \% \mathrm{Su}$ had the highest values of $\Delta H_{T}$ over the range of the studied temperatures $\left(7-30^{\circ} \mathrm{C}\right)$. The results demonstrate that this combination of sweeteners $(75 \% \mathrm{St}+25 \% \mathrm{Su})$ can provide a higher stability to white chocolate against possible fluctuations in storage temperature that can affect the chocolate properties.

The results of the energy required for completing the melting of the polymorphic form $\mathrm{V}\left(\Delta H_{\text {melt }}\right)$ are presented in Fig. 1B. The values of $\Delta H_{\text {melt }}$ were also influenced by fat content, as previously found for parameter $\Delta H_{T}$. The samples $100 \% \mathrm{St}, 50 \% \mathrm{St}+25 \% \mathrm{Su}$ and $75 \% \mathrm{St}+25 \% \mathrm{Su}$ stored at $15{ }^{\circ} \mathrm{C}$ presented a statistically higher $\Delta H_{\text {melt }}$ values than $100 \% \mathrm{Su}$. Besides, the samples $50 \% \mathrm{St}+25 \% \mathrm{Su}$ and $75 \% \mathrm{St}+25 \% \mathrm{Su}$ at higher temperatures $\left(30^{\circ} \mathrm{C}\right)$ presented higher $\Delta H_{\text {melt }}$ values than their counterparts with the same fat content values $(50 \% \mathrm{St}+50 \% \mathrm{Su}$ and $100 \% \mathrm{Su})$, demonstrating a higher stability at higher temperatures due to a less reduction of the $\Delta H_{\text {melt }}$ value. Both samples showed a decrease in the parameter $\Delta H_{\text {melt }}$ when the storage temperature increased from 7 to $30^{\circ} \mathrm{C}$. This was similar to the case of the control sample $100 \% \mathrm{~S}(\cong 5 \%)$ when tested against other samples that showed a statistically greater reduction of $\Delta H_{\text {melt }}(18 \%-35 \%)$. This behavior would indicate that the presence of St and the combination of St with Su $(75 \% \mathrm{St}+25 \% \mathrm{Su})$ stabilizes the matrix at higher storage temperatures. Therefore, these samples require more energy to melt, resisting higher temperatures without melting, giving to the chocolate greater stability at higher storage temperatures. Also, provided better stability against possible temperature fluctuations during storage, thus preventing the melting, and consequent fat Bloom formation on the surface of the chocolate. 

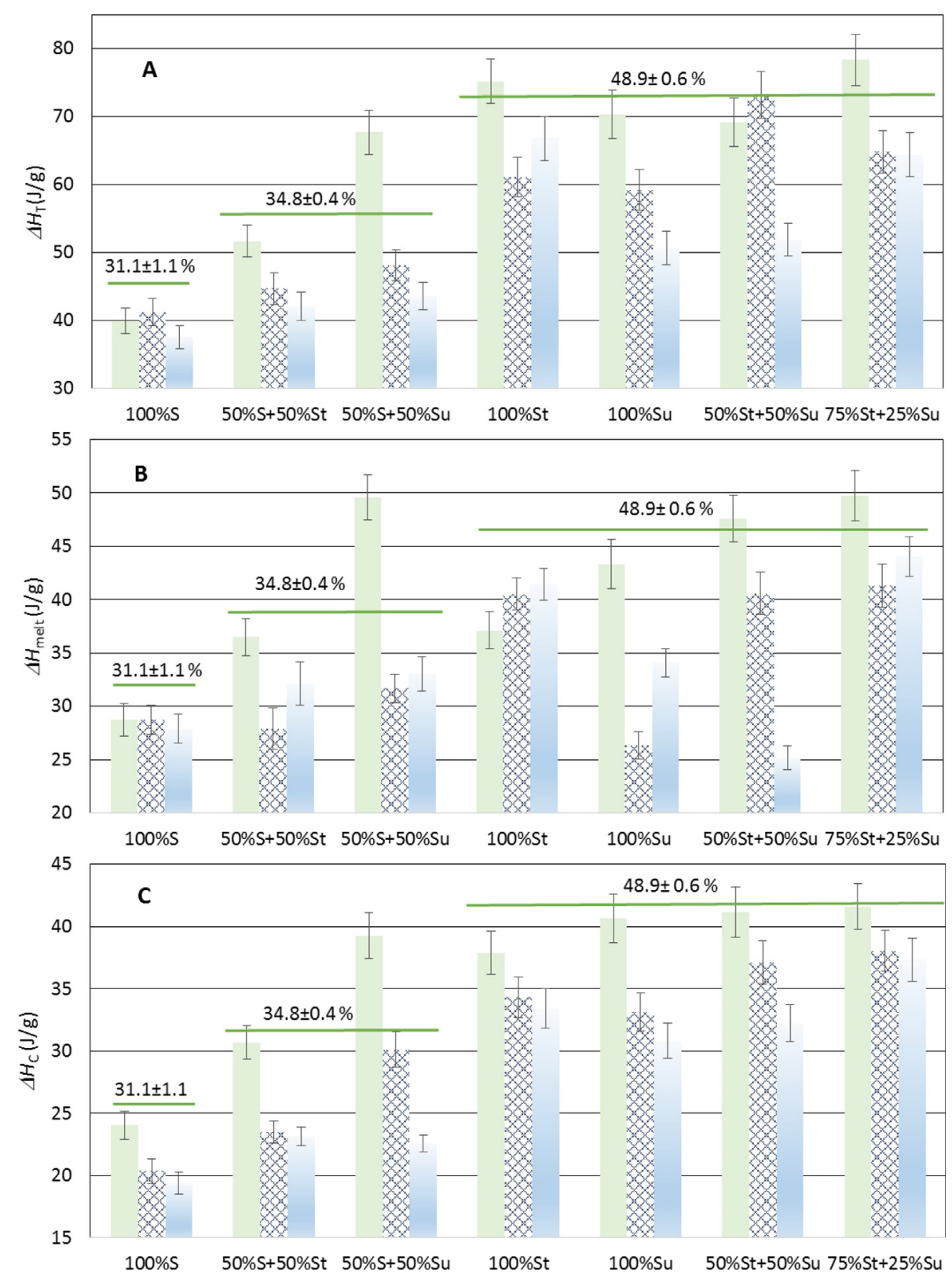

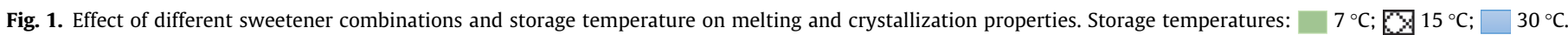
$\mathrm{A}=\Delta H_{T} ; \mathrm{B}=\Delta H_{\text {melt }} ; \mathrm{C}=\Delta H_{c}$. The fat content of each sample are indicated in the image.

Fig. 1C shows crystallization enthalpies; $\Delta H_{c}$ increases with the increase of fat content. However, by comparing samples with a total replacement of sucrose and the same fat content $(48.9 \pm 0.6 \%, w / w)$, a synergistic effect was observed for the binary combination of Su and St. Indeed, the sample $75 \% \mathrm{St}+25 \% \mathrm{Su}$ presented a constant value of $\Delta H_{c}$ throughout the studied temperature range. In addition, this sample showed a value of $\Delta H_{c}$ statistically higher at a storage temperature of $30^{\circ} \mathrm{C}$ with respect to the samples with the same fat content $(100 \% \mathrm{St}, 100 \% \mathrm{Su}, 50 \% \mathrm{St}$ $+50 \% \mathrm{Su})$.

Table 1 shows the end temperature $\left(T_{\text {end }}\right)$. Values were higher when the storage temperature changed from $7{ }^{\circ} \mathrm{C}$ to $30^{\circ} \mathrm{C}$ for samples $100 \% \mathrm{~S}, 100 \% \mathrm{St}, 100 \% \mathrm{Su}, 50 \% \mathrm{~S}+50 \% \mathrm{Su}, 50 \% \mathrm{St}+50 \% \mathrm{Su}$ indicating a delay in the finish of melting. However, the samples $50 \% \mathrm{~S}$ $+50 \%$ St and $75 \%$ St $+25 \%$ Su showed no difference with the increase of storage temperature $(P>0.05)$. Besides, the $T_{\text {end }}$ value at $\mathrm{T}=30^{\circ} \mathrm{C}$ of the sample $75 \% \mathrm{St}+25 \% \mathrm{Su}$ was significantly lower with respect to the formulation $50 \% \mathrm{~S}+50 \%$ St. No statistically significant differences with the rest of the samples studied and stored at low temperature $\left(7^{\circ} \mathrm{C}\right)$ was found. Therefore, the sample $75 \% \mathrm{St}+25 \%$ Su took less time in completing the melting than the other freesugar samples, presenting a good stability at elevated temperatures, and preserving its physical properties. This behavior of sample $75 \% \mathrm{St}+25 \% \mathrm{Su}$ is important because it is related to the temporal components of flavor release and oral epithelial sensation (Aidoo, Afoakwa, \& Dewettinck, 2015).

The results obtained for the peak maximum $\left(T_{\text {peak }}\right)$ temperature at which melting rate is the greatest, are also shown in Table 1. The samples with a single sweetener (100\%S, $100 \%$ St and $100 \% \mathrm{Su}$ ) showed an increase in $T_{\text {peak }}$ values (polyform $\mathrm{V}$ ) with an increase of storage temperature from 7 to $30^{\circ} \mathrm{C}$ (Table 1 ), demonstrating a change in the internal structure of the matrix which affects their physical properties. However, in the case of the samples with a combination of sweeteners, the $T_{\text {peak }}$ value remained constant during the studied period when increasing the storage temperature. The samples $100 \% \mathrm{~S}, 100 \% \mathrm{St}$ and $100 \% \mathrm{Su}$, stored at $7{ }^{\circ} \mathrm{C}$, showed sta- 
Table 1

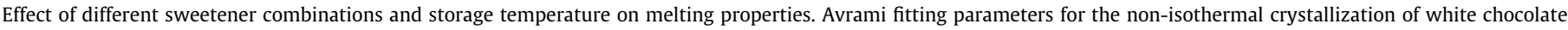
samples. ${ }^{a}$

\begin{tabular}{|c|c|c|c|c|c|c|}
\hline Sample $^{1}$ & Storage temperature $\left({ }^{\circ} \mathrm{C}\right)$ & $T_{\text {end }}\left({ }^{\circ} \mathrm{C}\right)$ & $T_{\text {peak }}\left({ }^{\circ} \mathrm{C}\right)$ & $E a(\mathrm{~kJ} / \mathrm{mol})$ & $A(1 / \mathrm{min})$ & $R^{2}$ \\
\hline $100 \% S$ & $\begin{array}{l}7 \\
15 \\
30\end{array}$ & $\begin{array}{l}36.22 \pm 1.07 \\
36.34 \pm 0.98 \\
37.54 \pm 1.01\end{array}$ & $\begin{array}{l}31.63 \pm 0.65 \\
31.75 \pm 0.48 \\
32.33 \pm 0.39\end{array}$ & $\begin{array}{l}62.1 \pm 3.2^{\mathrm{a}} \\
86.6 \pm 3.9^{\mathrm{b}} \\
60.0 \pm 3.2^{\mathrm{a}}\end{array}$ & $\begin{array}{l}8.14 \times 10^{12} \\
3.60 \times 10^{17} \\
3.93 \times 10^{12}\end{array}$ & $\begin{array}{l}0.94 \\
0.94 \\
0.91\end{array}$ \\
\hline $100 \%$ St & $\begin{array}{l}7 \\
15 \\
30\end{array}$ & $\begin{array}{l}36.37 \pm 0.78 \\
36.29 \pm 1.02 \\
37.11 \pm 0.89\end{array}$ & $\begin{array}{l}31.84 \pm 0.42 \\
32.43 \pm 0.57 \\
32.77 \pm 0.52\end{array}$ & $\begin{array}{l}83.1 \pm 4.2^{b} \\
107.0 \pm 4.3^{c} \\
65.8 \pm 3.9^{a}\end{array}$ & $\begin{array}{l}7.14 \times 10^{16} \\
1.93 \times 10^{21} \\
4.19 \times 10^{13}\end{array}$ & $\begin{array}{l}0.94 \\
0.94 \\
0.94\end{array}$ \\
\hline $100 \% \mathrm{Su}$ & $\begin{array}{l}7 \\
15 \\
30\end{array}$ & $\begin{array}{l}36.06 \pm 1.03 \\
37.64 \pm 0.79 \\
37.25 \pm 0.86\end{array}$ & $\begin{array}{l}30.97 \pm 0.69 \\
32.85 \pm 0.75 \\
32.72 \pm 0.68\end{array}$ & $\begin{array}{l}82.3 \pm 2.2^{\mathrm{b}} \\
66.3 \pm 3.2^{\mathrm{a}} \\
62.5 \pm 2.9^{\mathrm{a}}\end{array}$ & $\begin{array}{l}5.29 \times 10^{16} \\
5.04 \times 10^{13} \\
1.04 \times 10^{13}\end{array}$ & $\begin{array}{l}0.94 \\
0.90 \\
0.92\end{array}$ \\
\hline $50 \% S+50 \% S t$ & $\begin{array}{l}7 \\
15 \\
30\end{array}$ & $\begin{array}{l}37.07 \pm 0.54 \\
37.00 \pm 0.65 \\
37.27 \pm 0.45\end{array}$ & $\begin{array}{l}32.30 \pm 0.57 \\
32.57 \pm 0.49 \\
32.72 \pm 0.39\end{array}$ & $\begin{array}{l}61.6 \pm 2.9^{\mathrm{a}} \\
70.5 \pm 4.5^{\mathrm{b}} \\
64.3 \pm 3.8^{\mathrm{a}}\end{array}$ & $\begin{array}{l}6.25 \times 10^{12} \\
3.43 \times 10^{14} \\
2.52 \times 10^{13}\end{array}$ & $\begin{array}{l}0.91 \\
0.91 \\
0.92\end{array}$ \\
\hline $50 \% S+50 \% S u$ & $\begin{array}{l}7 \\
15 \\
30\end{array}$ & $\begin{array}{l}35.85 \pm 0.69 \\
36.22 \pm 0.87 \\
36.76 \pm 0.69\end{array}$ & $\begin{array}{l}32.39 \pm 0.43 \\
32.02 \pm 0.57 \\
32.49 \pm 0.65\end{array}$ & $\begin{array}{l}85.0 \pm 5.0^{\mathrm{b}} \\
105.2 \pm 5.6^{\mathrm{c}} \\
94.4 \pm 3.1^{\mathrm{c}}\end{array}$ & $\begin{array}{l}1.61 \times 10^{17} \\
4.30 \times 10^{20} \\
4.42 \times 10^{18}\end{array}$ & $\begin{array}{l}0.96 \\
0.96 \\
0.92\end{array}$ \\
\hline $50 \% \mathrm{St}+50 \% \mathrm{Su}$ & $\begin{array}{l}7 \\
15 \\
30\end{array}$ & $\begin{array}{l}36.57 \pm 0.72 \\
37.07 \pm 0.49 \\
37.13 \pm 0.63\end{array}$ & $\begin{array}{l}32.86 \pm 0.79 \\
33.38 \pm 0.36 \\
32.52 \pm 0.59\end{array}$ & $\begin{array}{l}82.5 \pm 4.7^{\mathrm{b}} \\
136.1 \pm 6.1^{\mathrm{d}} \\
118.8 \pm 5.1^{\mathrm{e}}\end{array}$ & $\begin{array}{l}5.48 \times 10^{16} \\
2.29 \times 10^{26} \\
1.59 \times 10^{23}\end{array}$ & $\begin{array}{l}0.97 \\
0.92 \\
0.92\end{array}$ \\
\hline $75 \% \mathrm{St}+25 \% \mathrm{Su}$ & $\begin{array}{l}7 \\
15 \\
30\end{array}$ & $\begin{array}{l}36.58 \pm 0.59 \\
36.38 \pm 0.57 \\
36.67 \pm 0.43\end{array}$ & $\begin{array}{l}32.69 \pm 0.54 \\
32.68 \pm 0.68 \\
32.50 \pm 0.57\end{array}$ & $\begin{array}{l}96.2 \pm 5.3^{\mathrm{c}} \\
162.3 \pm 7.8^{\mathrm{f}} \\
124.4 \pm 5.2^{\mathrm{e}}\end{array}$ & $\begin{array}{l}1.05 \times 10^{19} \\
1.58 \times 10^{31} \\
1.78 \times 10^{24}\end{array}$ & $\begin{array}{l}0.96 \\
0.91 \\
0.91\end{array}$ \\
\hline
\end{tabular}

\footnotetext{
1 S: sucrose; St: Stevia; Su: sucralose.
}

${ }^{a}$ Means with equal superscripts in each group for the same column are not significantly different $(P>0.05)$ by the Tukey's test.

tistically lower values of $T_{\text {peak }}$ with respect to the formulations with binary combinations of sweeteners $(P<0.05)$.These results are supported by previous studies performed by Afoakwa et al. (2008a) which demonstrated that $T_{\text {peak }}$ did not vary in chocolate with different fat contents. Therefore, the observed changes in these values are due to the different sweetener combinations.

\subsection{Effect of composition on crystallization kinetics of white chocolate}

Table 1 shows the kinetic parameters obtained from the studies of non-isothermal crystallization kinetics. The observed differences on $E a$ and $A$ can be due to the variations in the composition of the samples, which produce changes in the crystallinity. Crystallization kinetics was also influenced by the storage temperature, being the optimal one near $15^{\circ} \mathrm{C}$, except for the sample $100 \%$ Su that presented an optimal storage temperature at lower temperatures $\left(7^{\circ} \mathrm{C}\right)$. The reason of this, is because, at higher temperatures, the rate constant increases and viscosity of the medium decreases (Sierra Muñeton \& Katime, 2006).

The sample $75 \% \mathrm{St}+25 \% \mathrm{Su}$ presented the highest values of $\mathrm{Ea}$ for the all the storage temperature studied, even at elevated temperatures, indicating a greater stability than the other formulations studied against fluctuations in temperature during storage.

The relative crystallinity can be expressed as a function of crystallization temperature, as shown in Supplemental Fig. 1. All the curves presented similar sigmoidal shapes. As shown in Supplementary Fig. 1 the samples 50\%St $+50 \%$ Su and $75 \% \mathrm{St}+25 \%$ Su crystallized at higher temperatures, completing the crystallization process at higher temperatures. In Table 1 , it can be seen that these samples presented greater values of frequency constant $(A)$ than the other chocolate formulations. The frequency constant indicates the number of attempts per unit of time to overcome the energy barrier, thus the higher value of the frequency constant for the chocolate sample indicates that it has a greater tendency for crystallization (Vaish \& Varma, 2015). Therefore, the composition of a chocolate significantly affects cocoa butter crystallization, as was found in the research performed by Garti and Widlak (2012), who studied the influence of fat milk in the crystallization process of dark chocolate.

\subsection{Relationship between moisture content and firmness}

Fig. 2 shows an initial moisture content for the studied samples between $1.6 \%$ and $3.3 \%(\mathrm{w} / \mathrm{w})$. The samples with higher initial moisture content were the formulations with total replacement of sucrose by $100 \% \mathrm{St}, 100 \% \mathrm{Su}$ and $75 \% \mathrm{St}+25 \% \mathrm{Su}$. Studies performed by Ziegleder, Amanitis, and Hornik (2004) demonstrated that the moisture content of fresh white chocolate samples without sucrose replacement stored at $25{ }^{\circ} \mathrm{C}$ at a relative humidity of $55 \%$ were $2 \%(\mathrm{w} / \mathrm{w})$. This moisture content of the white chocolate can be due to the usual short conching times between 2 and $6 \mathrm{~h}$.

The absorption of water of the white chocolate samples during the storage at $20^{\circ} \mathrm{C}$ at a relative humidity of $55 \%$, depended only of the matrix composition, due to the permeability of the material and the extension of the storage time. Fig. 2 shows that the increase of moisture produces hardening of the chocolate sample. This is in agreement with previous studies performed by Shourideh, Taslimi, Azizi, and Mohammadifar (2012) who found that the moisture absorption caused chocolate hardness. The moisture migration can be due to the fact that sucrose and milk solids are embedded in a continuous fat crystal network with pores full or partially filled, where water can diffuse mainly through these void spaces to the interior of the sample (Ghosh, Ziegler, \& Anantheswaran, 2005). The migration of water may produce structural changes with the consequent liberation of moisture; causing modifications in food texture as shown in Fig. 2. The structural changes occurred approximately after 14 months of storage for most of the samples studied, except for the formulations $100 \% \mathrm{St}$ and $75 \% \mathrm{St}+25 \% \mathrm{Su}$. The change in behavior of the samples $100 \%$ St and $75 \% \mathrm{St}+25 \%$ Su must be due to the combinations of sweeteners used for replacement of sucrose, which modify microstructure and then the interactions of chocolate with the media, especially at elevated temperatures lowering the water absorption (Marín, Lemus, Flores, \& Vega, 2006). Fig. 3 shows the micrographs obtained from the SEM study; the micrographs of the samples $100 \%$ Su (Fig. 3C) and 50\% $+50 \%$ Su (Fig. 3E) presented open pores where water could diffuse. The moisture transference to chocolate will depend on the physical state of the fat, amount and type of hydrophilic constituents (Ghosh et al., 2005). The non-fat ingredi- 

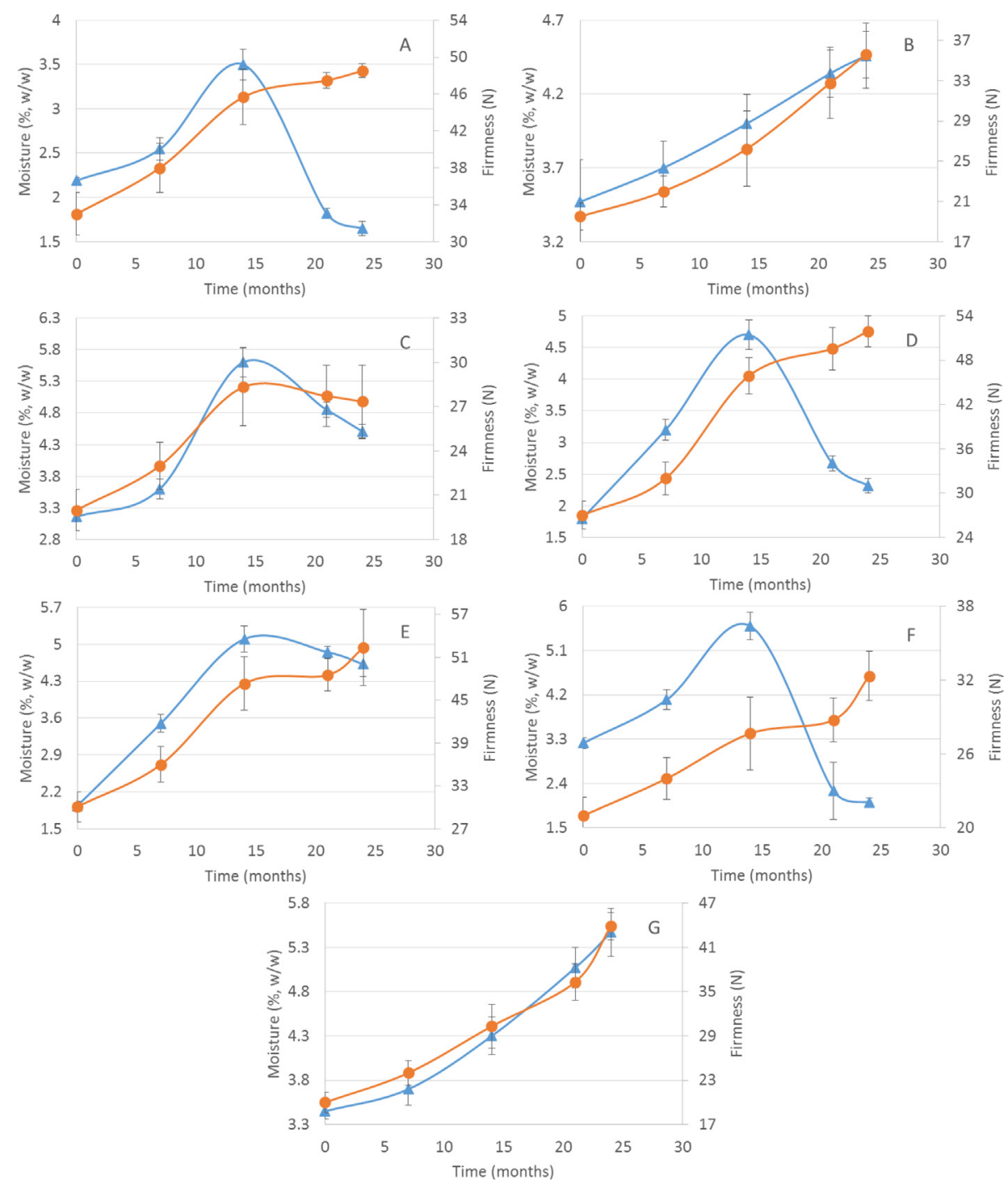

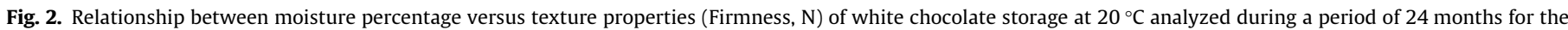
samples: (A) 100\%S, (B) 100\%St, (C) 100\%Su, (D) 50\%S + 50\%St, (E) 50\%S + 50\%Su, (F) 50\%St + 50\%Su, (G) $75 \%$ St + 25\%Su. $\bigcirc$ : Moisture percentage; $\triangle$; Firmness (N).

ents and the microstructure may influence the diffusion of water through the chocolate. Fig. 2 shows that water diffusion through the chocolate matrix depends on its composition and microstructure. Fig. 4 presents bloomed white chocolates, showing numerous and large re-crystallized fat crystals and sugar crystals. This recrystallization results in a polymorphic transformation by nucleation and growth with new large crystals that modify the crystalline structure, influencing the inter-crystal connections with impact on the mechanical properties (Afoakwa et al., 2009). The sample $75 \% \mathrm{St}+25 \% \mathrm{Su}$ presented a lower density of fat crystals on the surface (Fig. 4G), reflecting its higher stability against the formation of fat and sugar Bloom which may cause changes in the mechanical properties.

\subsection{Relationship between formation of Bloom and microstructure of white chocolate free of sucrose}

To observe the differences in the microstructure of the tested formulations, scanning electron microscopy was used showing variations in the crystalline network structure as a function of the sweetener combination (Fig. 3). The samples $100 \% \mathrm{~S}$ (Fig. 3A), $50 \%$ S $+50 \%$ St (Fig. 3D), $50 \%$ St $+50 \%$ Su (Fig. 3 F) and $75 \%$ St $+25 \%$ Su (Fig. $3 G$ ) presented denser surfaces; however, the samples $100 \%$
Su (Fig. 3C) and 50\%S + 50\%Su (Fig. 3E) presented surfaces with cracks or void spaces. This confers to the matrix of white chocolate a lower integrity, diminishing its stability against different processes of quality deterioration. Besides, sample $100 \%$ St presented a rough surface (Fig. 3B). Studies performed by Bui and Coad (2014) showed evidence of the appearance of surface roughness in chocolate micrographs stored at elevated temperatures $\left(30^{\circ} \mathrm{C}\right)$. As was previously described, Fig. $3 \mathrm{E}$ shows the micrographs obtained for sample $50 \% \mathrm{~S}+50 \%$ Su that presented a surface with cracks or void spaces which may lead to a greater contact with oxidizing compounds such as oxygen, justifying its higher peroxide index (Supplementary Table 1).

From the percentage of fat and sugar Bloom (\% Bloom) values at 85 days of storage $\left(T=15^{\circ} \mathrm{C}\right)$, Scheffe canonical equation was obtained, in which only the terms that were statistically significant $(P<0.05)$ were considered:

$\%$ Bloom $=8.54 \mathrm{~S}+7.78 \mathrm{St}+133.84 \mathrm{~S} \mathrm{Su}-20.17 \mathrm{St} \mathrm{Su}$

The model adequately fits the data with $P<0.05$, a $95 \%$ confidence limit and $R^{2}=0.9999$. A significant antagonistic effect for the sample $50 \% \mathrm{~S}+50 \% \mathrm{Su}$, and a significant synergistic effect for the combination of Stevia and sucralose were observed, because the binary combinations presented higher and lower values, respectively, that the samples containing the individual compo- 

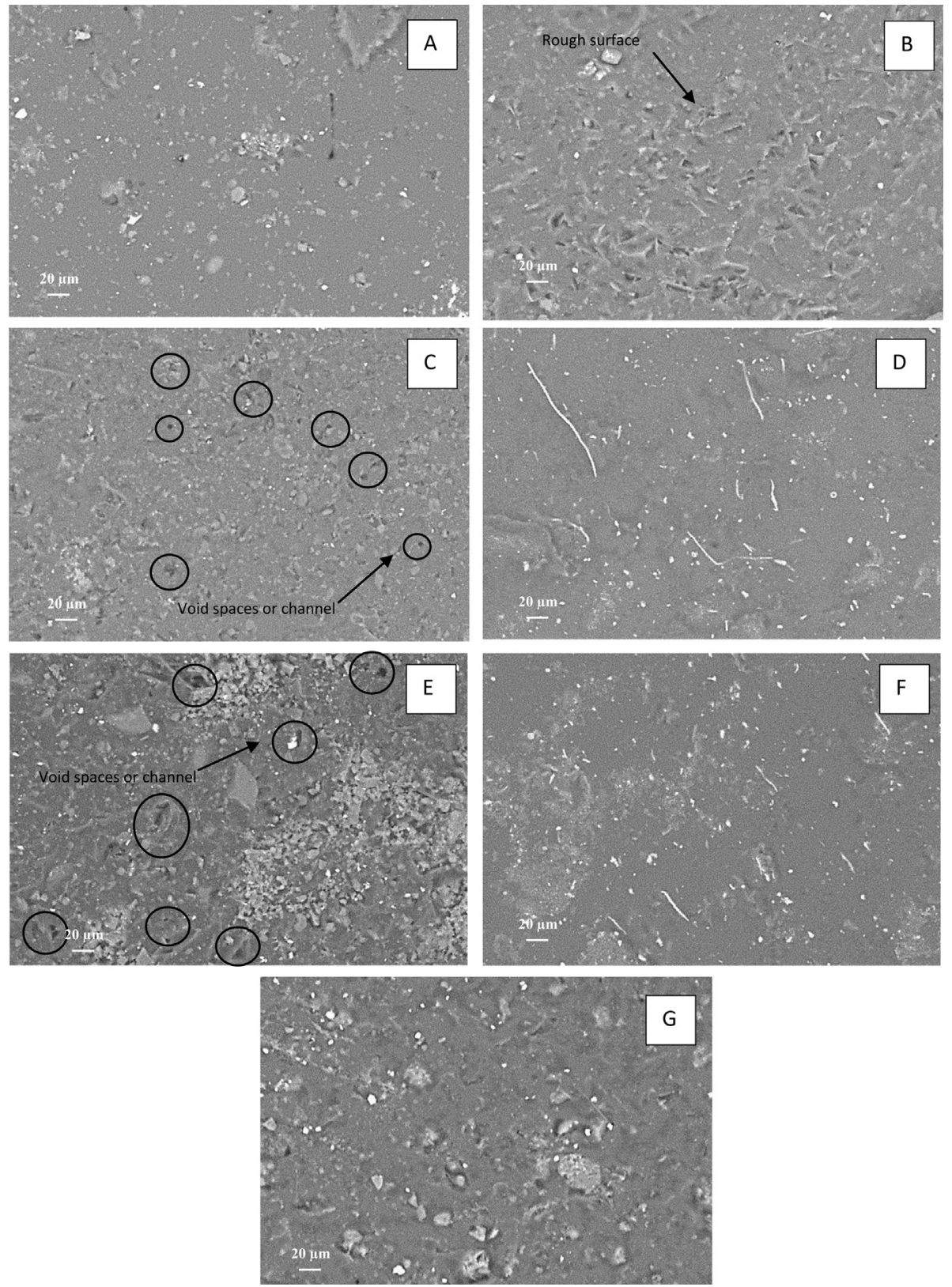

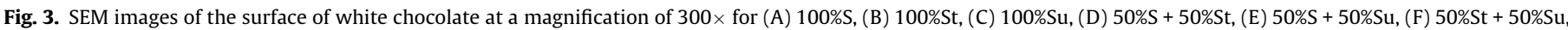
(G) $75 \% \mathrm{St}+25 \% \mathrm{Su}$

nents. From Eq. (13), the response surface graph shown in Supplementary Fig. 2 was generated. The highest values of Bloom observed in the left-hand side of the graph correspond to the binary combination of the sweetener sucrose and sucralose $(50 \% \mathrm{~S}$ $+50 \% \mathrm{Su}$ ). The trends described before may be associated with the microstructure of the different formulations. The sample with the highest Bloom\% shows a surface with void spaces like channels (Fig. 3E), limiting the particle-particle interaction strength. These channels would facilitate the fat migration through the matrix of chocolate, and subsequently its recrystallization on the surface. Besides, the absorption of moisture may lead to the diffusion of the solid particles through these channels and the crystallization at the surface of the amorphous saccharides, influencing the highest percentage of Bloom (Shourideh et al., 2012). However, the\% Bloom value decreases to the right-hand side of the graph, reaching a minimum for samples containing Stevia (100\%St) and combinations of Stevia and sucralose $(50 \% \mathrm{St}+50 \% \mathrm{Su}$ and $75 \% \mathrm{St}+25 \% \mathrm{Su})$.
These samples presented minimal inter-particle spaces similar to the microstructure found in the control sample $(100 \% \mathrm{~S})$, showing a high solid packing, which minimized the migration of fat or solid particles to the surface (Fig. 3A), and their recrystallization. These results are important because, according to previous studies performed by Afoakwa, Paterson, Fowler, and Vieira (2008b), the blooming showed a great effect on the texture, since harder chocolates were obtained, attributable to the re-crystallization process underwent by the fat.

Fig. 4 shows the bloomed samples of white sucrose-free chocolate. The $50 \% \mathrm{~S}+50 \% \mathrm{Su}$ (Fig. $4 \mathrm{E}$ ) sample presented large fat crystals, reaching sizes of $175 \mu \mathrm{m}$ with a mean size of $46.52 \pm 4.78 \mu \mathrm{m}$. As was previously described, the $100 \% \mathrm{Su}$ (Fig. $4 \mathrm{C}$ ) and $50 \% \mathrm{~S}+50 \% \mathrm{Su}$ (Fig. 4E) samples presented a marked presence of channels or cracks in the chocolate surface, through which the solid particles and fats may diffuse and recrystallize on the chocolate surface. The $75 \% \mathrm{St}+25 \% \mathrm{Su}$ sample (Fig. $4 \mathrm{G}$ ) presented the lowest density 

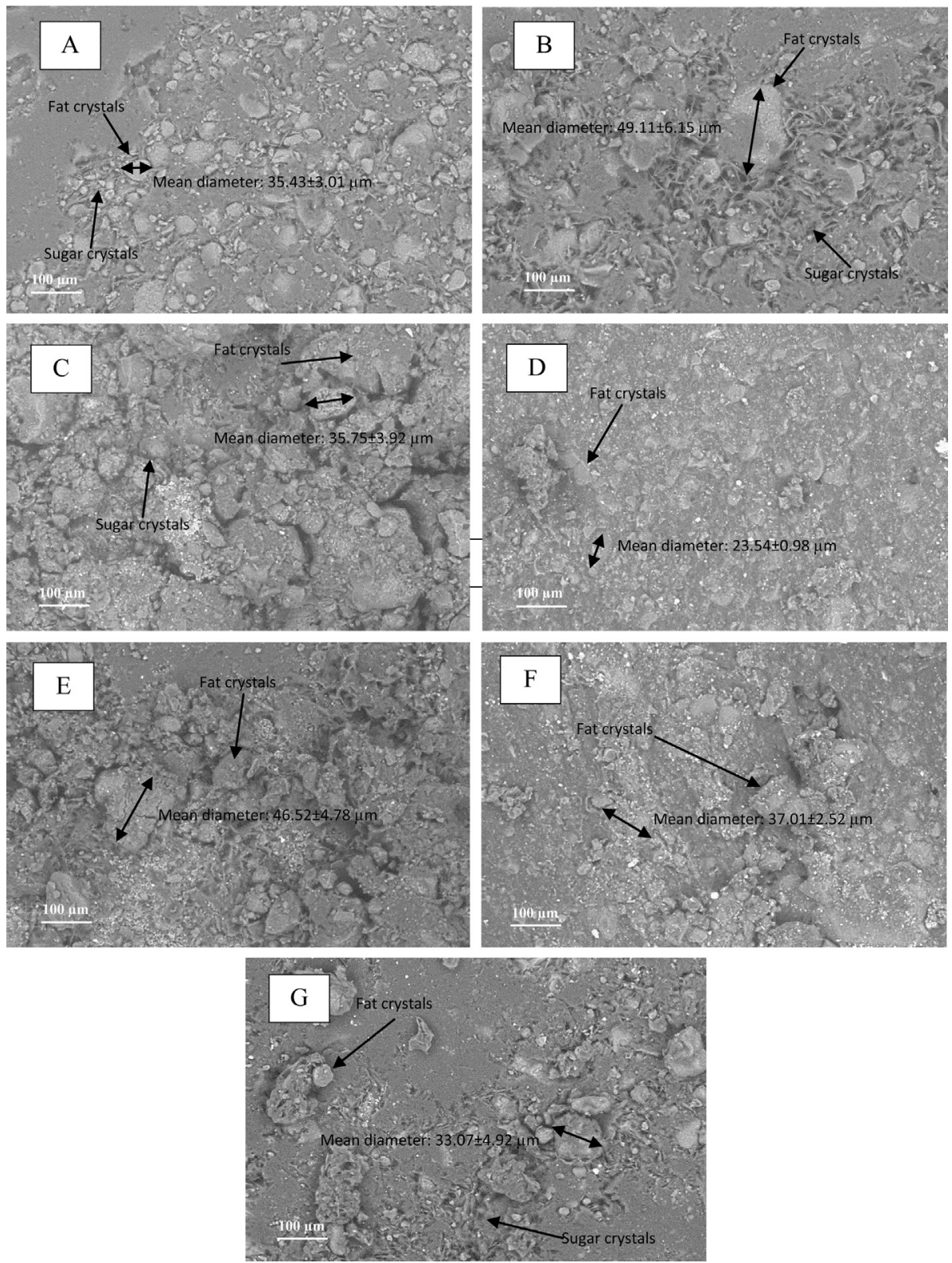

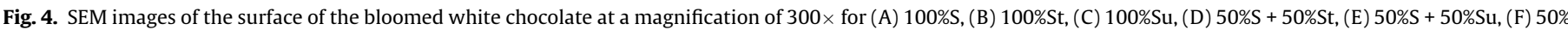
St $+50 \%$ Su, (G) $75 \%$ St $+25 \%$ Su.

of fat crystals on the surface, reflecting its reduced tendency to Bloom formation during the storage time studied.

4.6. Relationship among color, \% Bloom and microstructure of white chocolate free of sucrose

Table 2 shows the results obtained for parameters $a^{*}, b^{*}$ and $L^{*}$ and the calculated value $E_{a b}^{*}$ for samples stored at $\mathrm{T}=15^{\circ} \mathrm{C}$, analyzed during a 100-day period. The $L^{*}$ values of the samples presented fluctuations during the studied storage period, remaining almost constant, except for the samples $50 \% \mathrm{~S}+50 \% \mathrm{Su}$ that presented a decrease between 43 and 100 days of storage. This decrease in lightness may be due to the formation of fat crystals on the surface of chocolate (Bloom), probably causing the dispersion of light (Afoakwa et al. (2008b)). However, the values of $a^{*}$ and $b^{*}$ increased and decreased, respectively, during the 100days period analyzed. However the values of $a^{*}$ were closer to "0". This may be due to the formation of Bloom on the surface, according to studies reported by Afoakwa et al. (2008b), generating a whitish surface. However, $100 \%$ S and $75 \%$ St $+25 \%$ Su samples presented a particular behavior, since the parameter $a^{*}$ increased statistically between 8 and 29 days of storage, and then, it remained constant during the period analyzed (Table 2).

The calculated $E_{a b}^{*}$ values presented an increase at day 100 of storage when a statistically significant increase was observed. The increasing of $E_{a b}^{*}$ may be due to the Bloom, where the clusters of fat crystals may have scattered the light, as previously described by Briones and Aguilera (2005) and Shourideh et al. (2012) who studied the effects of a sucrose replacer by low digestible carbohydrates (inulin and D-tagatose) on dark chocolate formulas. Besides, this effect could be due to the sugar and sweetener recrystallization on chocolate surface. However, the $75 \% \mathrm{St}+25 \% \mathrm{Su}$ sample was the only one that did not show a statistically significant difference in $E_{a b}^{*}$ during the period analyzed, corroborating previous results in which formation of Bloom was not observed (values closer to zero). 
Table 2

Color parameters $\left(a^{*}, b^{*}\right.$ and $\left.L^{*}\right)$ and the calculated value of $E_{a b}^{*}$ for the white chocolate formulas tested during a storage period of 100 days storage at $15^{\circ} \mathrm{C}$.

\begin{tabular}{|c|c|c|c|c|c|}
\hline Sample $^{1}$ & Time (days) & $a^{*}$ & $b^{*}$ & $L^{*}$ & $E_{a b}^{*}$ \\
\hline $100 \% S$ & $\begin{array}{l}1 \\
8 \\
29 \\
43 \\
100\end{array}$ & $\begin{array}{l}-0.92 \pm 0.12^{\mathrm{a}} \\
-0.89 \pm 0.14^{\mathrm{a}} \\
-0.56 \pm 0.13^{\mathrm{b}} \\
-0.61 \pm 0.08^{\mathrm{b}} \\
-0.52 \pm 0.10^{\mathrm{b}}\end{array}$ & $\begin{array}{l}24.10 \pm 0.22^{\mathrm{a}} \\
24.56 \pm 0.18^{\mathrm{a}} \\
25.49 \pm 0.27^{\mathrm{b}} \\
24.39 \pm 0.18^{\mathrm{a}} \\
21.23 \pm 0.47^{\mathrm{c}}\end{array}$ & $\begin{array}{l}82.65 \pm 0.82^{\mathrm{a}} \\
82.75 \pm 0.52^{\mathrm{a}} \\
82.78 \pm 1.50^{\mathrm{a}} \\
82.05 \pm 0.23^{\mathrm{a}} \\
81.27 \pm 1.87^{\mathrm{a}}\end{array}$ & $\begin{array}{l}0.00 \pm 0.00^{\mathrm{a}} \\
0.00 \pm 0.00^{\mathrm{a}} \\
0.98 \pm 0.01^{\mathrm{b}} \\
0.77 \pm 0.01^{\mathrm{c}} \\
4.08 \pm 0.04^{\mathrm{d}}\end{array}$ \\
\hline $100 \% \mathrm{St}$ & $\begin{array}{l}1 \\
8 \\
29 \\
43 \\
100\end{array}$ & $\begin{array}{l}-1.01 \pm 0.08^{\mathrm{a}} \\
-1.10 \pm 0.04^{\mathrm{a}} \\
-0.78 \pm 0.01^{\mathrm{b}} \\
-0.73 \pm 0.11^{\mathrm{b}} \\
-0.48 \pm 0.14^{\mathrm{c}}\end{array}$ & $\begin{array}{l}28.00 \pm 0.38^{\mathrm{a}} \\
28.06 \pm 0.32^{\mathrm{a}} \\
28.61 \pm 0.22^{\mathrm{a}} \\
28.15 \pm 0.11^{\mathrm{a}} \\
22.70 \pm 0.59^{\mathrm{b}}\end{array}$ & $\begin{array}{l}79.73 \pm 0.36^{\mathrm{a}} \\
79.69 \pm 0.48^{\mathrm{a}} \\
81.08 \pm 0.40^{\mathrm{a}} \\
78.81 \pm 0.18^{\mathrm{b}} \\
81.93 \pm 0.28^{\mathrm{a}}\end{array}$ & $\begin{array}{l}0.00 \pm 0.00^{\mathrm{a}} \\
0.00 \pm 0.00^{\mathrm{a}} \\
1.53 \pm 0.02^{\mathrm{b}} \\
0.96 \pm 0.01^{\mathrm{c}} \\
5.84 \pm 0.06^{\mathrm{d}}\end{array}$ \\
\hline $100 \% \mathrm{Su}$ & $\begin{array}{l}1 \\
8 \\
29 \\
43 \\
100\end{array}$ & $\begin{array}{l}-1.24 \pm 0.04^{\mathrm{a}} \\
-1.21 \pm 0.03^{\mathrm{a}} \\
-0.91 \pm 0.05^{\mathrm{b}} \\
-0.93 \pm 0.03^{\mathrm{b}} \\
-0.81 \pm 0.01^{\mathrm{c}}\end{array}$ & $\begin{array}{l}27.42 \pm 0.32^{\mathrm{a}} \\
27.21 \pm 0.18^{\mathrm{a}} \\
28.13 \pm 0.31^{\mathrm{b}} \\
27.64 \pm 0.09^{\mathrm{a}} \\
24.13 \pm 0.76^{\mathrm{c}}\end{array}$ & $\begin{array}{l}81.78 \pm 0.27^{\mathrm{a}} \\
81.94 \pm 0.16^{\mathrm{a}} \\
82.63 \pm 0.17^{\mathrm{a}} \\
80.79 \pm 0.16^{\mathrm{b}} \\
79.29 \pm 1.83^{\mathrm{a}, \mathrm{b}}\end{array}$ & $\begin{array}{l}0.00 \pm 0.00^{\mathrm{a}} \\
0.00 \pm 0.00^{\mathrm{a}} \\
1.19 \pm 0.01^{\mathrm{b}} \\
1.26 \pm 0.01^{\mathrm{c}} \\
4.51 \pm 0.05^{\mathrm{d}}\end{array}$ \\
\hline $50 \% S+50 \% S t$ & $\begin{array}{l}1 \\
8 \\
29 \\
43 \\
100\end{array}$ & $\begin{array}{l}-1.12 \pm 0.08^{\mathrm{a}} \\
-1.16 \pm 0.05^{\mathrm{a}} \\
-0.96 \pm 0.01^{\mathrm{b}} \\
-1.00 \pm 0.03^{\mathrm{b}} \\
-0.48 \pm 0.11^{\mathrm{c}}\end{array}$ & $\begin{array}{l}25.48 \pm 0.22^{\mathrm{a}} \\
25.27 \pm 0.17^{\mathrm{a}} \\
26.05 \pm 0.14^{\mathrm{b}} \\
24.93 \pm 0.12^{\mathrm{c}} \\
21.79 \pm 0.51^{\mathrm{d}}\end{array}$ & $\begin{array}{l}81.32 \pm 0.38^{\mathrm{a}} \\
81.59 \pm 0.02^{\mathrm{a}} \\
82.02 \pm 0.40^{\mathrm{a}} \\
80.51 \pm 0.20^{\mathrm{b}} \\
78.98 \pm 3.10^{\mathrm{a}, \mathrm{b}}\end{array}$ & $\begin{array}{l}0.00 \pm 0.00^{\mathrm{a}} \\
0.00 \pm 0.00^{\mathrm{a}} \\
0.91 \pm 0.01^{\mathrm{b}} \\
1.15 \pm 0.01^{\mathrm{c}} \\
4.63 \pm 0.05^{\mathrm{d}}\end{array}$ \\
\hline $50 \% S+50 \% S u$ & $\begin{array}{l}1 \\
8 \\
29 \\
43 \\
100\end{array}$ & $\begin{array}{l}-1.32 \pm 0.07^{\mathrm{a}} \\
-1.39 \pm 0.02^{\mathrm{a}} \\
-1.11 \pm 0.04^{\mathrm{b}} \\
-0.99 \pm 0.14^{\mathrm{b}, \mathrm{c}} \\
-0.91 \pm 0.04^{\mathrm{c}}\end{array}$ & $\begin{array}{l}25.81 \pm 0.11^{\mathrm{a}} \\
25.88 \pm 0.07^{\mathrm{a}} \\
26.55 \pm 0.16^{\mathrm{b}} \\
25.57 \pm 0.06^{\mathrm{a}} \\
21.67 \pm 0.01^{\mathrm{c}}\end{array}$ & $\begin{array}{l}82.12 \pm 0.28^{\mathrm{a}} \\
82.38 \pm 0.01^{\mathrm{a}} \\
83.38 \pm 0.32^{\mathrm{b}} \\
80.79 \pm 0.45^{\mathrm{c}} \\
81.64 \pm 0.58^{\mathrm{c}}\end{array}$ & $\begin{array}{l}0.00 \pm 0.00^{\mathrm{a}} \\
0.00 \pm 0.00^{\mathrm{a}} \\
1.23 \pm 0.01^{\mathrm{b}} \\
1.68 \pm 0.02^{\mathrm{c}} \\
4.31 \pm 0.05^{\mathrm{d}}\end{array}$ \\
\hline $50 \% S t+50 \% S u$ & $\begin{array}{l}1 \\
8 \\
29 \\
43 \\
100\end{array}$ & $\begin{array}{l}-1.38 \pm 0.08^{\mathrm{a}} \\
-1.44 \pm 0.02^{\mathrm{a}} \\
-1.19 \pm 0.02^{\mathrm{b}} \\
-1.12 \pm 0.17^{\mathrm{b}} \\
-0.45 \pm 0.14^{\mathrm{c}}\end{array}$ & $\begin{array}{l}25.99 \pm 0.21^{\mathrm{a}} \\
25.87 \pm 0.12^{\mathrm{a}} \\
26.53 \pm 0.24^{\mathrm{b}} \\
25.78 \pm 0.19^{\mathrm{a}} \\
23.88 \pm 0.05^{\mathrm{c}}\end{array}$ & $\begin{array}{l}80.62 \pm 0.16^{\mathrm{a}} \\
80.98 \pm 0.12^{\mathrm{a}} \\
81.72 \pm 0.39^{\mathrm{b}} \\
79.88 \pm 0.19^{\mathrm{c}} \\
80.22 \pm 0.52^{\mathrm{a}, \mathrm{b}, \mathrm{c}}\end{array}$ & $\begin{array}{l}0.00 \pm 0.00^{\mathrm{a}} \\
0.00 \pm 0.00^{\mathrm{a}} \\
1.02 \pm 0.01^{\mathrm{b}} \\
1.15 \pm 0.01^{\mathrm{c}} \\
2.27 \pm 0.02^{\mathrm{d}}\end{array}$ \\
\hline $75 \% S t+25 \% S u$ & $\begin{array}{l}1 \\
8 \\
29 \\
43 \\
100\end{array}$ & $\begin{array}{l}-0.88 \pm 0.06^{\mathrm{a}} \\
-0.93 \pm 0.02^{\mathrm{a}} \\
-0.50 \pm 0.03^{\mathrm{b}} \\
-0.41 \pm 0.11^{\mathrm{b}} \\
-0.67 \pm 0.21^{\mathrm{b}}\end{array}$ & $\begin{array}{l}26.61 \pm 0.23^{\mathrm{a}} \\
26.82 \pm 0.10^{\mathrm{a}} \\
27.41 \pm 0.05^{\mathrm{b}} \\
26.13 \pm 0.10^{\mathrm{a}} \\
23.45 \pm 0.02^{\mathrm{c}}\end{array}$ & $\begin{array}{l}81.36 \pm 0.18^{\mathrm{a}} \\
81.28 \pm 0.13^{\mathrm{a}} \\
82.25 \pm 0.15^{\mathrm{b}} \\
80.19 \pm 0.07^{\mathrm{c}} \\
81.15 \pm 0.77^{\mathrm{a}, \mathrm{b}, \mathrm{c}}\end{array}$ & $\begin{array}{l}0.00 \pm 0.00^{\mathrm{a}} \\
0.00 \pm 0.00^{\mathrm{a}} \\
0.01 \pm 0.01^{\mathrm{a}} \\
0.01 \pm 0.01^{\mathrm{a}} \\
0.04 \pm 0.04^{\mathrm{a}}\end{array}$ \\
\hline
\end{tabular}

1 S: sucrose; St: Stevia; Su: sucralose.

a Means with equal superscripts in each group for the same column are not significantly different $(P>0.05)$ by the Tukey's test.

The $100 \%$ St sample showed the greatest increase of $E_{a b}^{*}$, probably due to the roughening of the surface (Fig. 3B). This may be attributed to the partial melting of cocoa butter fractions, which allows the movement of the solid components (James \& Smith, 2009). According to the DSC studies, carried out in the present work these samples showed polymorphic form I which exhibited melting temperatures of $18.52^{\circ} \mathrm{C}$ and $18.66^{\circ} \mathrm{C}$, lower than the storage temperature. The $50 \% \mathrm{~S}+50 \% \mathrm{St}$ sample also presented crystallizations of polyform I (Melting temperature $=18.97^{\circ} \mathrm{C}$ ); however, due to their high content of solid particles in suspension (partial replacement of sucrose, Supplementary Table 1), the diffusion rate of fat was reduced, probably preventing the appearance of surface roughening (Fig. 3D). Besides, the fat in the product with a low melting point tends to migrate towards the chocolate surface, producing crystallization and Bloom (Altimiras et al., 2007).

Another source of fat Bloom is related to storage temperature, where low-melting point crystals melt, migrate to the surface and recrystallize without occasion for re-tempering (Beckett, 2000).

\section{Conclusions}

The results show that the partial or total replacement of sucrose by sweeteners modifies the stability, texture, moisture content, percentage of Bloom formation, and thermodynamic properties. The highest values of activation energy $(E a)$ were found for the sample $75 \% \mathrm{St}+25 \% \mathrm{Su}$, coinciding with the formulation with a minimum formation of Bloom on the surface during storage and minor color changes.
A relationship between the microstructure and the percentage of Bloom formation on the surface of chocolate was found. Samples containing $100 \% \mathrm{Su}$ and $50 \% \mathrm{~S}+50 \% \mathrm{Su}$ presented a microstructure with channels or open spaces through which solids and fat can spread more easily to the surface, causing an increase of the Bloom formation on the surface. However, samples with $50 \% \mathrm{St}+50 \% \mathrm{Su}$ and $75 \% \mathrm{St}+25 \% \mathrm{Su}$ presented minimal Bloom formation on the chocolate surface due to a dense microstructure without void spaces, minimizing the diffusion of fat and solids to the surface.

The DSC studies revealed that the increase of the storage temperature produced a decrease of $\Delta H_{\text {melt }}$ which would make the samples more prone to cause the formation of Bloom on chocolate surface. However, sample with $75 \% \mathrm{St}+25 \% \mathrm{Su}$ presented the lowest decrease of $\Delta H_{\text {melt }}$ and the highest values of $E a$ throughout the studied storage temperatures range $\left(7-30^{\circ} \mathrm{C}\right)$, demonstrating a greater stability of this sample against possible fluctuations of the temperature during storage. Therefore, the formulation of sucrose-free white chocolate with a combination of sweeteners (75\%St $+25 \% \mathrm{Su})$ offers a greater stability against different storage conditions constituting an added value to the product.

\section{Acknowledgments}

Financial support provided by the Secretaria de Ciencia y Tecnica (SCyT), Universidad Nacional de San Luis (Project 22Q/411) and Proyecto de Investigación Científica y Tecnológica (PICT) 2012-0155 (ANPCyT) are gratefully acknowledged. 


\section{Appendix A. Supplementary data}

Supplementary data associated with this article can be found, in the online version, at http://dx.doi.org/10.1016/j.foodchem.2017. 03.002 .

\section{References}

Afoakwa, E. O., Paterson, A., Fowler, M., \& Vieira, J. (2008a). Characterization of melting properties in dark chocolates from varying particle size distribution and composition using differential scanning calorimetry. Food Research International, 41, 751-757.

Afoakwa, E. O., Paterson, A., Fowler, M., \& Vieira, J. (2008b). Effects of tempering and fat crystallisation behaviour on microstructure, mechanical properties and appearance in dark chocolate systems. Journal of Food Engineering 89, 128-136.

Afoakwa, E. O., Paterson, A., Fowler, M., \& Vieira, J. (2009). Influence of tempering and fat crystallization behaviours on microstructural and melting properties in dark chocolate systems. Food Research International, 42, 200-209.

Aidoo, R. P., Afoakwa, E. O., \& Dewettinck, K. (2015). Rheological properties, melting behaviours and physical quality characteristics of sugar-free chocolates processed using inulin/polydextrose bulking mixtures sweetened with stevia and thaumatin extracts. LWT - Food Science and Technology, 62, 592-597.

Altimiras, P., Pyle, L., \& Bouchon, P. (2007). Structure-fat migration relationships during storage of cocoa butter model bars: Bloom development and possible mechanisms. Journal of Food Engineering, 80(2), 600-610.

Arshad, M. A., \& Maaroufi, A. (2015). Relationship between Johnson-Mehl-Avrami and Šesták-Berggren models in the kinetics of crystallization in amorphous materials. Journal of Non-Crystalline Solids, 413, 53-58.

Beckett, S. T. (2000). The science of chocolate. Cambridge: Royal Society of Chemistry.

Briones, V., \& Aguilera, J. M. (2005). Image analysis of changes in surfaces color of chocolate. Food Research International, 38, 87-94.

Bui, L. T. T., \& Coad, R. (2014). Military ration chocolate: The effect of simulated tropical storage on sensory quality, structure and bloom formation. Food Chemistry, 160, 365-370.

Chiari, Y. L., Vadlamudi, M., Chella, R., Jeon, K., \& Alamo, R. G. (2007). Overall crystallization kinetics of polymorphic propyleneethylene random copolymers: A two-stage parallel model of Avrami kinetics. Polymer, 48, 3170-3182.

Fernandes, V. A., Müller, A. J., \& Sandoval, A. J. (2013). Thermal, structural and rheological characteristics of dark chocolate with different compositions. Journal of Food Engineering, 116, 97-108.

Ferreira, S. L. C., Bruns, R. E., Paranhos da Silva, E. G., dos Santos, W. N. L., Quintella, C. M., David, J. M., ... Neto, B. B. (2007). Statistical designs and response surface techniques for the optimization of chromatographic systems. Journal of Chromatography A, 1158, 2-14.

Frazier, A., \& Hartel, R. W. (2012). Bloom on chocolate chips baked in cookies. Food Research International, 48, 380-386.

Garti, N., \& Widlak, N. R. (2012). Cocoa butter and related compounds (p. 386). United States of America: AOCS Press.

Ghosh, V., Ziegler, G. R., \& Anantheswaran, R. C. (2005). Moisture migration through chocolate-flavored confectionery coatings. Journal of Food Engineering, 66, 177-186.
Gómez Polo, C., Portillo Muñoz, M., Cruz Lorenzo, M., Luengo, P. V., Galindo, P. D. M. D., \& Martín Casado, A. M. (2016). Comparison of the CIELab and CIEDE2000 color difference formulas. The Journal of Prosthetic Dentistry, 115(1), 65-70.

Himawan, C., Starov, V. M., \& Stapley, A. G. F. (2006). Thermodynamic and kinetic aspects of fat crystallization. Advances in Colloid and Interface Science, 122, 3-33.

James, B. J., \& Smith, B. G. (2009). Surface structure and composition of fresh and bloomed chocolate analysed using X-ray photoelectron spectroscopy, cryoscanning electron microscopy and environmental scanning electron microscopy. LWT - Food Science and Technology, 42, 929-937.

Kim, I. S., Yang, M., Lee, O. H., \& Kang, S. N. (2011). The antioxidant activity and the bioactive compound content of Stevia rebaudiana water extracts. LWT - Food Science and Technology, 44, 1328-1332.

Lindsey, D. T., \& Wee, A. G. (2007). Perceptibility and acceptability of CIELAB color differences in computer-simulated teeth. Journal of Dentistry, 35, 593-599.

Málek, J. (1995). The applicability of Johnson-Mehl-Avrami model in the thermal analysis of the crystallization kinetics of glasses. Thermochimica Acta, 267 $61-73$.

Málek, J. (2000). Kinetic analysis of crystallization processes in amorphous materials. Thermochimica Acta, 355, 239-253.

Marín, B. E., Lemus, M. R., Flores, M. V., \& Vega, G. A. (2006). Rehydration of dehydrated foods. La rehidratación de alimentos deshidratados. Revista Chilena de Nutrición, 33(3), 0-19.

Ries, A., Canedo, E. L., Monteiro, A. E. G., de Almeida, Y. M. B., \& Wellen, R. M. R. (2016). Model-free non-isothermal crystallization kinetics of poly(3hydoxybutyrate) filled with carbon black. Polymer Testing, 50, 241-246.

Rodriguez Furlán, L. T., Baracco, Y., Lecot, J., Zaritzky, N., \& Campderrós, M. E. (2017). Influence of hydrogenated oil as cocoa butter replacers in the development of sugar-free compound chocolates: Use of inulin as stabilizing agent. Food Chemistry, 217, 637-647.

Rodriguez Furlán, L. T., Baracco, Y., Zaritzky, N., \& Campderrós, M. E. (2016a). Influence of sucralose and Stevia on the physicochemical properties of free sugar chocolate. Asian Journal of Science and Technology, 7(7), 3227-3234.

Rodriguez Furlán, L. T., Baracco, Y., Zaritzky, N., \& Campderrós, M. E. (2016b). Development of free sugar white chocolate, suitable for diabetics, using Stevia and sucralose as sweeteners: Study of the thermal degradation kinetic International Journal of Research in Advent Technology, 4(7), 49-57.

Sammons, R., \& Marquis, P. (1997). Application of the low vacuum scanning electron microscope to the study of biomaterials and mammalian cells Biomaterials, 18, 81-86.

Shourideh, M., Taslimi, A., Azizi, M. H., \& Mohammadifar, M. A. (2012). Effects of DTagatose and inulin on some physicochemical, rheological and sensory properties of dark chocolate. International Journal of Bioscience, Biochemistry and Bioinformatics, 2(5), 314-319.

Sierra Muñeton, J. D., \& Katime, I. (2006). Crystallization kinetics of ethylene/acrylic acid copolymers. Cinética de cristalización de copolímeros de etileno/ácido acrílico. Revista Iberoamericana de Polímeros, 7(1), 7-42.

Vaish, R., \& Varma, K. B. R. (2015). The glass transition and crystallization kinetic studies on BaNaB9015 glasses https://arxiv.org/ftp/arxiv/papers/0909/0909. 0114.pdf.

Vercet, A. (2003). Browning of white chocolate during storage. Food Chemistry, 81, 371-377.

Ziegleder, G., Amanitis, A., \& Hornik, H. (2004). Thickening of molten white chocolates during storage. LWT - Food Science and Technology, 37, 771-778. 